\title{
REVISIÓN
}

REVIEW

\section{SUPERVIVENCIA DEL INJERTO GRASO. FACTORES PRONÓSTICOS}

\author{
SURVIVAL OF THE FATTY GRAFT. PROGNOSTIC FACTORS \\ Alicia María Tamayo Carbón', Yiraldi Yanet Bencosme Escarramán 2 , Rolando Ernesto \\ Medina Robainas ${ }^{3}$
}

\section{RESUMEN}

Utilizar la grasa del propio paciente como material de elección para restaurar volúmenes permite describir distintas formas de obtención de la misma; con o sin infiltración de la zona donante, distintas presiones negativas de succión; diferentes tipos de procesamiento (lavado, filtrado, decantación o centrifugación) y varias formas de implantarla según el plano utilizado, el grosor de los depósitos, la separación de los mismos entre sí, con resultados muy dispares. Para aumentar el volumen de una región, basta con obtener grasa y colocarla en el sitio deseado, siempre sobrevivirá una parte del injerto y siempre existirá una célula madre propia dirigiendo el proceso regenerativo. Pero, ¿cómo lograr que sobreviva todo el tejido trasplantado? La diversidad de criterios aún discutibles, unido a la falta de métodos objetivos no invasivos de evaluación de la sobrevida de los adipocitos, hacen que surja la necesidad de establecer las variables predictoras de supervivencia del lipoinjerto

\section{ABSTRACT}

Using the patient's own fat as the material of choice to restore volumes has led to the description of different ways of obtaining it; with or without infiltration of the donor area, different negative suction pressures; different types of processing (washing, filtering, decanting or centrifuging) and various ways of implanting it according to the plane used, the thickness of the deposits, their separation from each other, with very different results. To increase the volume of a region, it is enough to obtain fat and place it in the desired site, a part of the graft will always survive and there will always be its own stem cell directing the regenerative process. But how to make all the transplanted tissue survive? The diversity of still debatable criteria, together with the lack of objective non-invasive methods to assess adipocyte survival, lead to the need to establish the predictive variables for lipograft survival.

\section{INTRODUCCIÓN}

La lipotransferencia es el autotrasplante de grasa, también llamado injerto de tejido adiposo, lipofilling, lipoinjerto, lipoestructura; es un procedimiento que utiliza la propia grasa de una persona para llenar defectos de tejido con cobertura como surcos, depresiones e irregularidades de origen congénito, adquirido o involutivo. ${ }^{1,2,3}$ Está contraindicado de manera absoluta en infecciones locales o sistémicas, y relativa en pacientes con trastornos de la coagulación. ${ }^{3}$ Las enfermedades que afectan la microcirculación como la diabetes mellitus constituyen un riesgo para la supervivencia del tejido trasplantado pero no una contraindicación. ${ }^{2}$

Las discrepancias surgidas en este tema tienen como fundamento lograr una mayor supervivencia del injerto para un mejor resultado. fgh En este proceso intervienen disimiles factores que se pueden agrupar en tres momentos del procedimiento: la obtención; la manipulación y su fijación.

Cuando se trata de un lipoinjerto a cada uno de esos pasos se le suman múltiples variables. Así, la obtención del injerto puede verse modificada por la selección de la zona donante ya que el tejido adiposo está distribuido en todo el cuerpo humano; el método anestésico dada la toxicidad de los medicamentos que puede afectar la viabilidad de las células; el instrumental empleado para liposucción (cánulas y jeringuillas); el método de liposucción y presión de aspiración, entre otros. En la manipulación del injerto influirá desde el sistema empleado (abierto o cerrado), con exposición o no del tejido adiposo a la agresión ambiental; hasta la forma de procesamiento (decantación, lavado, centrifugación, emulsión, filtración). Respecto a la fijación se añaden como variables modificables, el instrumental para colocarlo (punta, diámetro y número de orificios de la cánula); el
Médico especialista de II grado en Cirugía Plástica y Cau matología, profesor asistente e investigador auxiliar, Jefe de servicio Cirugía Plástica y Quemados, Hospital clínico quirúrgico "Hermanos Ameijeiras". La Habana, Cuba.

${ }_{2}^{2}$ Médico residente de tercer año de Cirugía Plástica y Caumatología. Hospital clínico quirúrgico "Hermanos Ameijeiras". La Habana, Cuba.

${ }^{3}$ Médico especialista de I grado en Cirugía Plástica y Caumatología. Hospital clínico quirúrgico "Hermanos Ameijeiras". La Habana, Cuba

Correspondencia a:

Yiraldi Yanet Bencosme Escarramán

Correo electrónico:y_yanet09@ hotmail.com

Telefono: +1(809)543-0934

ORCID: https://orcid.org/00000001-9275-1655

https://orcid.org/0000-00030344-5059

https://orcid.org/0000-00025006-266X

Palabras clave: injerto, regeneración, necrosis grasa, células madre.

Keywords: graft, regeneration, fat necrosis, stem cells

Procedencia y arbitraje: no comisionado, sometido a arbitraje externo.

Recibido para publicación: 8 de junio de 2020 Aceptado para publicación: 20 de diciembre de 2020

Citar como:

Tamayo Carbón AM, Bencosme Escarramán YY, Medina

Robainas RE. Supervivencia del injerto graso. factores pronósticos. Rev Cient Cienc Med 2020; 23(2): 231-239 
área receptora (mientras mejor vascularizada mayor posibilidad de supervivencia); la manera de colocarlo (velocidad, presión ejercida, tamaño del depósito); el plano de colocación (existen diferencias que defienden por un lado la zona mejor irrigada y por el otro la zona que mayor similitud guarde con el origen del tejido trasplantado); la movilidad de la zona receptora pues una de las premisas para el prendimiento de un injerto es la inmovilidad.

La lipotransferencia es una de las opciones reconstructivas más antiguas de la especialidad, que quedo en desuso con los malos resultados a consecuencia de la falta de intervención en los elementos anteriormente señalados. La lipotransferencia se conoce como injerto desde 1890. En 1986 Ellenbogen publicó resultados usando depósitos de grasa de $6 \mathrm{~mm}$ de diámetro en el tratamiento estético de la cara. La popularidad de los injertos grasos en los últimos 20 años se ha incrementado de la mano del aumento de los procedimientos de liposucción y la disponibilidad de tejido graso. ${ }^{6}$

Con la identificación y perfeccionamiento de cada factor influyente en la supervivencia del lipoinjerto y el descubrimiento de las células madre pluripotenciales derivadas del tejido adiposo (ASC), se retoma esta técnica de lipotransferencia, ya no solo con fines reconstructivos sino también estéticos.

El auge de la terapia regenerativa vinculada a la cirugía plástica y la medicina antienvejecimiento, aportaron un vehículo enriquecedor que sumado al lipoinjerto podría aumentar su supervivencia. La presente revisión tiene como objetivo recopilar información que permita un acercamiento al protocolo más seguro de lipotransferencia en aras de garantizar una mayor sobrevida y permanencia del tejido adiposo trasplantado.

\section{METOdOLOGÍA DE BÚSQUEDA DE IN- FORMACIÓN}

Se construyeron descriptores en ciencias de salud DeCS - MESH y se hizo búsqueda en Medline, Pubmed, Scielo y ScienceDirect, utilizando descriptores en inglés: stem cells, adipose tissue, graft, adipocytes, mediante el conector booleano AND encontrando 35 citas relacionadas con exactitud del tema, revisadas con sus respectivas referencias, utilizando un total de 53 referencias bibliográficas pertinentes para el desarrollo. Se siguió el protocolo PRISMA (preferred reporting items for Systematic Reviews and Meta-analysis)

\section{DESARROLLO}

Existen dos teorías para el prendimiento del injerto: la teoría de la sobrevida y la teoría de la regeneración (Figura 1). La comprensión de este mecanismo permite considerar que para incrementar la zona de supervivencia es importante garantizar el cumplimiento de múltiples principios. $^{7}$

Poder utilizar la propia grasa de los pacientes como elección para restaurar volúmenes ha hecho que se describan formas diferentes de extracción, preparación y fijación de la misma; con resultados dispares. Profundizar en el mecanismo mediante el cual cada paso del autotrasplante actúa en el prendimiento del injerto graso, será de utilidad para aclarar las variables predictoras de su supervivencia.

1.Discrepancias en la obtención del injerto.

La obtención de ASC se realiza de diferentes zonas donantes para lo cual varios autores señalan la mejor. Fulton y col refieren que los muslos son el mejor sitio donante de tejido graso autólogo ${ }^{8}$, Mc Kinney y Pandya optan por la región abdominal suprapúbica, donde afirman que la grasa parece ser más densa y granular, mejorando resultados cosméticos y con menor reabsorción postinfiltracion ${ }^{9}$, al igual que Schipper quien demostró que las ASC de las regiones superficiales del abdomen son más resistentes a la apoptosis ya que la pared abdominal es una zona habitual de depósito graso, la cual proporciona un $5 \%$ de ASC frente a un $1 \%$ en la zona de la cadera, brazo, cara interna de muslos, área trocantérea y regiones profundas del abdomen ${ }^{10,11}$. Trepsat menciona la cara medial de la rodilla como zona ideal para trasplante en regiones periorbitarios señalando que la grasa es menos fibrosa ${ }^{11}$. Otros autores señalan que los mejores sitios son la cara interna de los muslos y la parte inferior del abdomen, ya que además de accesibles, son las mejores áreas donantes de ASC y de concentrado de adipocitos, demostrándose, que los adipocitos con receptores alpha 2 localizados en abdomen y trocánteres poseen pobre respuesta a la dieta y se mantienen con pocos cambios frente al aumento o disminución de peso, siendo antilipolíticos y con mayor posibilidad de supervivencia después de 


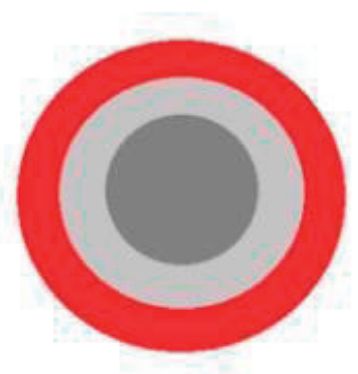

Necrosis.

Regeneración.

Sobrevida

Figura 1: Zonas de la biología del injerto

ser trasplantados. ${ }^{12}$

El anestésico usado para la obtención del injerto es discutido, autores reportan reducción de la viabilidad celular y mala diferenciación en adipocitos maduros al usar anestésicos locales, por lo que prefieren anestesia general. El tiempo transcurrido entre la infiltración de anestésico local y aspiración puede ser relevante respecto al contacto más prolongado entre células y anestésico ${ }^{9}$. Dada la posible toxicidad con la aplicación de anestésicos locales, algunos recomiendan la individualización por paciente prefiriendo la dosis más baja efectiva posible. 13,14 Otros expertos optan por la realización de infiltración tumescente con vasoconstrictor en la pared abdominal con el paciente bajo anestesia general. ${ }^{15,16}$

En el mecanismo usado en el proceso de obtención Yoshimura señala la diferencia entre aspirado y obtención por escisión, donde el tejido aspirado tiene menos ASC y adipocitos que el bloque obtenido por lipectomia, y por ello defienden la necesidad de enriquecer el aspirado con ASC. Para Pu, el número de células puede que sea el mismo pero la función de los adipocitos en el tejido aspirado es menor. Coleman defiende la obtención atraumática de la grasa con cánulas romas de $3 \mathrm{~mm}$ y jeringas de 10 mm, centrifugación a 3000 rpm durante 3 minutos para separar los componentes sanguíneos y células rotas ${ }^{9}$. Carpaneda y Ribeiro comparan la viabilidad de diversos cilindros de grasa y encuentran que la supervivencia es mayor en los que tienen menos de $3 \mathrm{~mm}$ de diámetro, la parte central de los injertos de más de 3.5 mm se necrosa9,17 (Figura 2). Illouz refiere que la grasa recogida mediante sistemas de aspiración potentes se encuentra en una forma más desorganizada que el tejido adiposo original por lo que puede sobrevivir en la zona receptora obteniendo sus nutrientes por ósmosis antes de la neovascularización. Mak cita que la liposucción se debe hacer usando una jeringa mejor que por aspiración para minimizar el trauma ${ }^{9}$. Se encontró que el tejido que se obtiene a través de lipoaspirado permite la liberación de un gran número de células con la morfología requerida. Por el contrario, el obtenido de abdominoplastia requiere procedimientos más extensos, donde se incluya la separación de la epidermis y la dermis, la disgregación mecánica del tejido adiposo aislado y la liberación de las células ${ }^{18}$. Por disgregación enzimática se obtiene un número mayor de células adherentes con las muestras de lipoaspirado más que con la de abdominoplastia, con alto potencial de proliferación, alcanzando la confluencia celular en aproximadamente dos semanas con una adherencia más rápida que con las células obtenidas por disgregación mecánica. Romanov reportó que la eficiencia del aislamiento de ASC bajo las condiciones de obtención mecánica es comparable a la obtenida con métodos enzimáticos, mientras que la eficiencia de adhesión al sustrato fue aún mayor que con la disgregación enzimática. ${ }^{19,20}$

Se ha visto que el uso de máquina de liposucción a una atmósfera daña más la integridad de la membrana del adipocito, y que las técnicas atraumáticas los mantienen con mejor función celular, permitiendo así una mayor supervivencia de los mismos. ${ }^{21,22}$ Es por ello que los métodos más recomendados son los que emplean jeringa y succión de pared o máquina de lipo- 

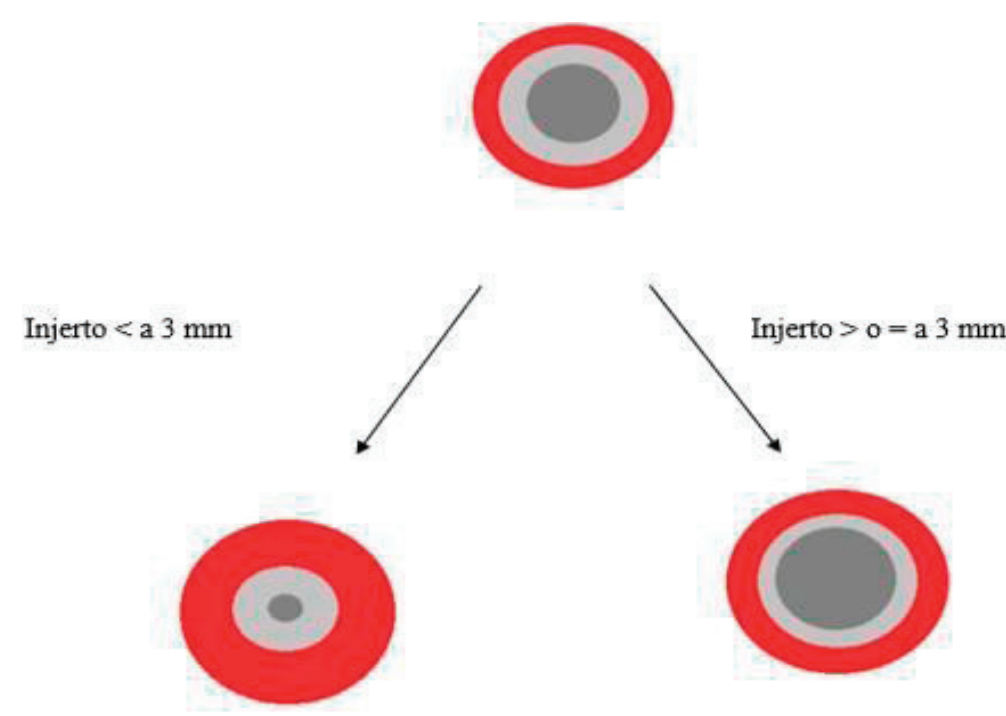

Adipocito - ASC

Adipocito - ASC $-600-1200$ ym

Adipocito - ASC $-100-300$ yol

Necrosis.

Regeneración.

Sobrevida

Figura 2: Injerto $<3 \mathrm{~mm}$ : Representa una mayor área de sobrevida y pequeña la zona de necrosis por un mejor contacto entre injerto y zona receptora. Injerto $>/=3 \mathrm{~mm}$ : Representa una mayor área de necrosis por menor contacto entre injerto y zona receptora.

succión a una presión menor de una atmósfera. $\mathrm{Si}$ se requiere macroinjertos, se obtiene la grasa con máquina de liposucción a presión baja con cánulas de $3 \mathrm{~mm}$, mientras que, si se requiere microinjertos, el método de preferencia es el uso de jeringa de aspiración y cánulas de 18 G. ${ }^{12}$

La obtención con jeringa de 10 cc y tras aspirar 2 cc de aire da lugar a una presión negativa de 0.37 at. La jeringa de 50 cc llega a una presión de vacío de 0.76 at, Ould-Ali muestra que, a menor presión de vacío, mayor supervivencia de tejido adiposo y menos fibrosis, por tanto, o se usa la jeringa de 10 cc con el émbolo retirado 2 cc o un lipoaspirador a 0.5 at. $^{23}$

2.Discrepancias en el procesamiento del injerto

La forma de procesar la grasa después de su obtención para lograr su integración es uno de los puntos de diferencias. Los métodos más comunes son: sedimentación, filtración o centrifugación.

A mayor fuerza centrífuga se produce mayor fracción oleosa y de fluido. A partir de $400 \mathrm{rpm}$ ya se produce la separación de la fracción roja.
Tanto los adipocitos como las ASC aguantan fuerzas de centrifugación importantes, hasta $3000 \mathrm{rpm}$. El tejido adiposo que da origen al injerto es más rico en ASC que el aspirado, la centrifugación hace que el tejido se compacte y aumenta la concentración de ASC. ${ }^{23}$

La centrifugación concentra factores de crecimiento vascular-endotelial, angiogénico, y fibroblástico, los cuales quedan reunidos en el mismo segmento que las células adiposas y las ASC $^{24}$. Además de que elimina las células sanguíneas y los elementos tóxicos tales como interleucinas y citoquinas, que disminuyen la integración y supervivencia del injerto ${ }^{12,25}$. Entre la supervivencia y el aumento de la intensidad de la centrifugación, se ha observado la aparición de adipocitos distorsionados y fracturados de manera significativa cuando la velocidad alcanza 4.000 rpm, mientras que otros investigadores refieren que ya por encima de $3.000 \mathrm{rpm}$, el daño del adipocito es muy importante. De igual forma se ha encontrado daño dependiendo del tiempo de centrifugación, cuando supera 5 minutos, a pesar de una fuerza de 3.000 
rpm o menor, produce ruptura de las membranas del adipocito, irregularidades en su forma y fusión celular. ${ }^{26}$

Algunos autores recomiendan lavar la grasa para eliminar las células sanguíneas dañadas y evitar la actividad fagocitaria de los macrófagos sobre los adipocitos, otros indican que la decantación o el lavado pueden ser superiores respecto a la viabilidad celular, y que la centrifugación reduce el transporte de glucosa y por tanto la supervivencia. ${ }^{23}$

Nuevos protocolos sugieren que los mejores resultados se obtienen con centrifugado suave precedido de lavado. La centrifugación y la decantación eliminan $50-60 \%$ de células rojas y leucocitos; el filtrado y lavado eliminan $90 \%$. Aunque la decantación permite mayor cantidad de adipocitos viables, también es cierto que presenta mayor contaminación por células sanguíneas y menor concentración de ASC. ${ }^{26}$

En los macroinjertos se decanta durante 10 minutos para eliminar el líquido excedente, mientras que, en los microinjertos, se centrifuga durante 3 minutos a $3.000 \mathrm{rpm}$ para pasar la grasa obtenida a través de las microcánulas de infiltración que son romas y de calibre 16 a 18 G. ${ }^{12,27}$

Respecto a la temperatura, Matsumoto estudió la degeneración de la grasa y persistencia de adipocitos y ASC en muestras centrifugadas a temperatura ambiente, $4^{\circ} \mathrm{C}$ y a $-80^{\circ} \mathrm{C}$ durante 1 mes. A temperatura ambiente las ASC resisten $4 \mathrm{~h}$, pero a las 24 horas han desaparecido.

Si se preserva a $4^{\circ} \mathrm{C}$ el número de $\mathrm{ASC}$ se mantiene $24 \mathrm{~h}$, pero luego se reducen. Recomiendan hacer la transferencia en menos de 4 horas. Si se ha de enviar tejido adiposo para procesar y obtener ASC puede enfriarse a $4^{\circ} \mathrm{C}$, teniendo 24 horas para mantener las ASC9. Para Carvalho es posible obtener ASC en un número adecuado y mantener una viabilidad aceptable de adipocitos hasta $24 \mathrm{~h}$ después de la obtención a temperatura ambiente.23 Varios trabajos han mostrado que las ASC mantienen su capacidad proliferativa y de diferenciación tras la descongelación. De hecho, parece que las ASC del tejido adiposo son más potentes y robustas en cuanto a viabilidad y proliferación post criopreservación que las células mesenquimales de otros tejidos. ${ }^{9,} 28$

Respecto al cultivo, para Rehman las ASC secretaban hasta 5 veces más factores de crecimiento endotelial vascular al cultivarlas en condiciones de hipoxia; estas ASC incrementan el crecimiento de las células endoteliales y disminuye su apoptosis. ${ }^{29}$

Actualmente algunos profesionales aplican la técnica de Nanofat, útil para la bioestimulación. Se basa en la filtración y emulsión del tejido adiposo para obtener la fracción vascular estromal, rica en células CD34 con gran potencial estimulador hematopoyético. Sirve para desarrollar microcirculación, y factores de crecimiento que forman nuevos vasos sanguíneos y aumenta la supervivencia por regeneración celular. ${ }^{30}$ (Figura 3)

\section{Discrepancias en la fijación del injerto}

La nutrición del injerto depende de que se desarrollen exitosamente las fases de imbibición plasmática, revascularización y reorganización, que se fundamentan en el paso de líquidos a través de la capa de fibrina formada entre el injerto y la zona receptora en las primeras 48 a 72 horas; la anastomosis entre los capilares receptores y los del injerto, la invasión vascular entre ambas zonas, entre el tercer y quinto día; y la tercera fase donde los fibroblastos invaden la capa de fibrina en el décimo día. ${ }^{7}$ Teniendo en cuenta la biología del injerto se facilita el entendimiento de cómo actúa cada factor modificable de la sobrevida del mismo.

Inyectar grandes cantidades en bolos puede condicionar necrosis e inclusive infección. Estudios experimentales han encontrado mayor supervivencia del injerto graso al inyectar en el plano muscular o supramuscular, pero influye también el volumen y el área infiltrada, así como la propia técnica. El inyectar en múltiples pases, con varios túneles, pequeñas cantidades y múltiples niveles tisulares, garantiza una mayor vascularización y supervivencia de la grasa, obteniéndose revascularización de los injertos desde el séptimo día gracias a los factores de crecimiento angiogénico. ${ }^{12}$ Actualmente se evita infiltración en el plano muscular ya que en investigaciones se ha encontrado que la grasa infiltrada en el músculo puede difundir más rápido en la economía corporal a través del torrente circulatorio, lo que, relacionado a otros factores coadyuvantes, puede condicionar la aparición de un síndrome de embolismo graso, o en el peor de los casos, de una embolia grasa. ${ }^{31}$

Coleman recomienda el uso de cánulas atraumáticas de 2 a $3 \mathrm{~mm}$ y la infiltración en múltiples pases para asegurar el contacto del injerto con 


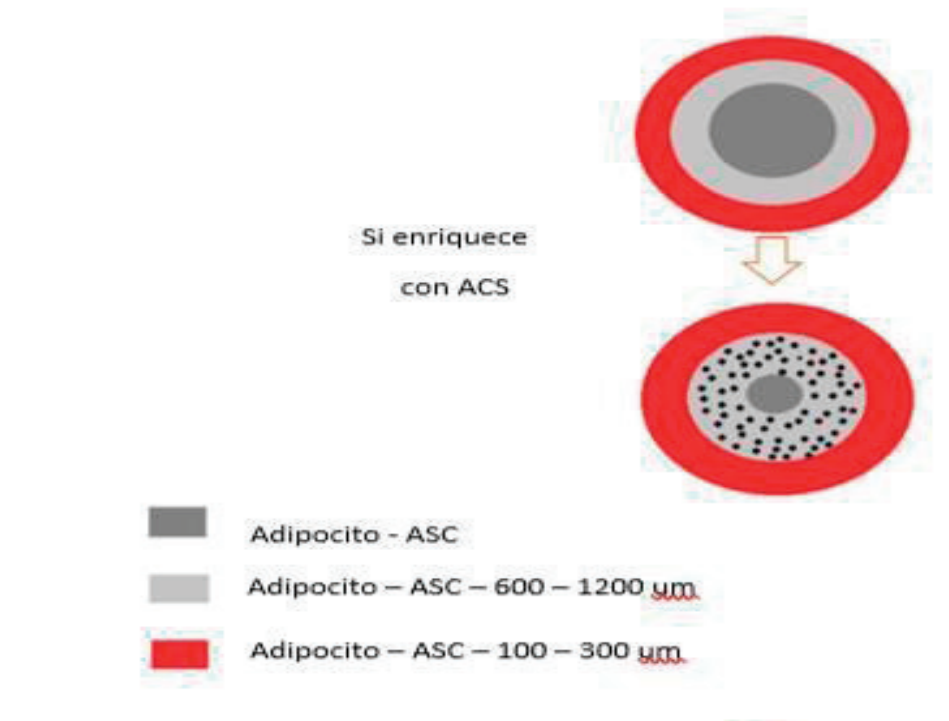

Necrosis.

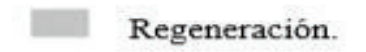

Sobrevida

Figura 3: Aumento de la zona de regeneración del injerto por acción de células madre.

el tejido receptor y su supervivencia. La presión de inyección no tiene importancia en la viabilidad, pero sí la velocidad de inyección, debido a la fuerza de cizallamiento, de forma que inyecciones lentas muestran una mejora en cuanto a supervivencia del 38\% en comparación a inyecciones rápidas ${ }^{9}$. Yoshimura ha demostrado que la adición de fracción estromal vascular mejora la supervivencia del lipoinjerto cuando éste se usa para dar volumen. Para la infiltración de macroinjertos en el lecho receptor se usa jeringas de 60 cc y cánulas romas de $3 \mathrm{~mm}$ con un solo orificio en la punta, en microinjertos se usa jeringas de 1 a 3 cc con microcánulas romas de 16 o 18 G. Esta diferencia se basa en los planos de infiltración y las necesidades que deben cubrir cada uno de ellos. Los macroinjertos se inyectan a través de las mismas incisiones empleadas para la liposucción o a través de pequeñas incisiones hechas con bisturí en las zonas apropiadas, mientras que los microinjertos se infiltran a través de incisiones realizadas con aguja hipodérmica de $18 \mathrm{G}$, por lo que el punto de acceso en este caso será prácticamente imperceptible. ${ }^{12,32}$

4.Discrepancias en los métodos de evaluación de supervivencia del injerto

A través del tiempo los autores han estudiado el porcentaje de reabsorción de tejido graso. En 1896 Verderame refirió que la tendencia del injerto a disminuir de volumen con el tiempo se debe a la reabsorción grasa por lo cual recomendó sobrecorregir los defectos. En 1950 Peer refiere la reabsorción de tejido injertado cercana al 50 \%. Según Matsudo y Toledo la reabsorción del 20 al 50\% de los injertos, para lo que realizan sobrecorrecciones del 35\% del volumen necesario para corregir el defecto. En 1988 Illouz encontró supervivencia de solo $20 \%$ de la grasa por lo cual aconseja sobrecorregir. En 1994 Carpaneda refiere una supervivencia del $40 \%$ del injerto graso, siempre y cuando el diámetro del filamento injertado sea menor de $3 \mathrm{~mm}$, porque demuestra que el injerto sobrevive por imbibición plasmática hasta $1.5 \mathrm{~mm}$ del borde vascularizado por lo que aconseja dejar espacios entre los filamentos. ${ }^{33}$

Muchos de los artículos publicados acerca del éxito de los injertos autólogos de grasa son subjetivos o semicuantitativos. Se recomienda la aplicación de principios fundamentales de la estereología. La cuantificación histológica toma mayor valor cuantas más medidas se realizan en distintos momentos del seguimiento postoperatorio, para apreciar así la progresión del comportamiento biológico del injerto afectado por el tiempo. ${ }^{33}$ La prueba confirmatoria de supervivencia de los autoinjertos es la demostración histológica. ${ }^{34,35}$ En las

muestras obtenidas mediante biopsia a los 
14 meses de seguimiento se evidencia menor cantidad de tejido viable, espacios pseudoquísticos, menor densidad de vasos sanguíneos y mayor componente fibroso en forma de bandas de tejido conjuntivo denso y pseudocápsula. ${ }^{33}$

\section{DISCUSIÓN}

El éxito en el trasplante de tejido adiposo depende de una estricta adherencia a los métodos más certeros de obtención, procesamiento y fijación del injerto. Respecto a la obtención la mayoría de los autores emplean como zona donante el abdomen, presión de aspiración ligera, cánulas de $3 \mathrm{~mm}$ de diámetro y anestesia general $^{11,15}$. Sin embargo, otros prefieren la anestesia local por la disminución de los riesgos y la pronta recuperación ${ }^{14}$.

Respecto al procesamiento todos los métodos son de utilidad. La decantación aporta un mayor volumen de adipocitos vivos ${ }^{26}$. La centrifugación concentra las células adiposas, los factores de crecimiento y las ASC al eliminar los restos hemáticos y anestésicos, y nunca debe exceder las $3000 \mathrm{rpm}^{23}$. El Nanofat emulsiona el injerto lo que hace que disminuya el volumen del mismo pero aumenta el porcentaje de $\mathrm{ASC}^{30}$. La comparación de la supervivencia del tejido trasplantado entre los diferentes métodos de procesamiento aún no se ha publicado. La adición de las ASC pudiera aumentar las posibilidades de sobrevida del tejido gracias al efecto angiogénico, inmunogénico y la terapia regenerativa que desencadenan. Sin embargo, en toda la lipotransferencia hay un número de ASC presentes. La proporción de las mismas en contraste con las células vivas tampoco se ha comparado según el método de preparación del tejido.

La fijación del injerto se ha visto mayor cuando se coloca en diferentes planos y pequeños depósitos, en una zona receptora muy bien vascularizada. Los métodos de evaluación aún carecen de estudios objetivos no invasivos ${ }^{12}$.

\section{CONCLUSIÓN}

Uno de los mayores problemas que se enfrenta actualmente para poder comparar los resultados de los diferentes autores y grupos de estudio es la falta de estandarización de los procedimientos. Existen numerosas variables que pueden alterar la supervivencia del injerto adiposo y servir para la predicción de los resultados. Los puntos de mayor coincidencia son: que la zona donante de preferencia es la región abdominal infraumbilical, se prefiere la anestesia general para disminuir el riesgo de toxicidad generada por anestésicos locales, la liposucción con jeringa es mejor que por aspiración para minimizar el trauma; que hay que procesar de alguna forma el tejido para eliminar la fracción roja y el fluido con elementos tóxicos y concentrar los adipocitos, factores de crecimiento y las células madre; que se puede almacenar el tejido a $4{ }^{\circ} \mathrm{C}$ durante 24 horas manteniendo la viabilidad celular al igual que las ASC son más potentes y robustas en cuanto a viabilidad y proliferación post criopreservación que las células mesenquimales de otros tejidos; que la implantación ha de ser atraumática y la infiltración en múltiples planos con pequeños volúmenes, simulando un panal de abejas, para asegurar el contacto del injerto con el tejido receptor y su sobrevida; que la supervivencia del injerto de grasa se evalúa con exactitud mediante estereología, la cual evidencia tejido adiposo viable en las zonas receptoras y su cuantificación mediante un método de determinación volumétri$\mathrm{co}$, en ausencia de otros procederes no invasivos para determinar resultados.

La lectura y revisión del tema muestra una amplia gama de acciones terapéuticas necesarias para realizar la lipotransferencia. La gran diversidad de criterios unido a la falta de métodos objetivos no invasivos de evaluación de la sobrevida de los adipocitos, hace que esta revisión cobre vigencia para poder predecir la supervivencia del tejido adiposo trasplantado. 


\section{REFERENCIAS}

1.Moredo $\mathrm{E}$, Pereira Dávalos $\mathrm{Cl}$, Valdés Collazo $\mathrm{C}$ Domínguez Sánchez Y. Facial deformity: a disability for his social repercussion. Revista Archivo del Hospital Universitario "General Calixto García" [Internet]. 2017 (Citado 2020 May 2); 5(2). DOI: http://www.revcalixto.sld.cu/index.php/ahcg/article/ view/229/202

2.Ruiz Matta JM, Peniche Castellanos A, Fierro Arias L, Arellano Mendoza MI, Ponce Olivera RM. Aumento de mentón mediante implante de grasa autóloga abdominal. Dermatol Rev Mex lnternet]. 2017 (citado 2020 May 2); 61(3):190-6. DOI:https://www.medigraphic.com/cgibin/new/resumen. cgi?IDARTICULO=73789

3.Blanco Moredo $\mathrm{E}$, Dunán Mesa L, Pérez Ferrer $M$. Lipotransfer: an alternative for the treatment of acquired facial deformity. Revista información científica [Internet]. 2020 (citado 2020 May 11); 99(1). DOI:http://scielo.sld.cu/scielo.php?script=sci_arttextelpid =S102899332020000100063\#B1.

4.Guzmán U, Clarisa J. Aumento de volumen 6́seo mediante injerto en bloque de la sínfisis. Universidad Privada de Tacna [Internet]. 2016 (citado 2020 May 4). Disponible en http://repositorio.upt.edu.pe/handle/ UPT/100

5.Hernández Sánchez $Y$, Sánchez Carbonell $Y$ Estrada Amador B. Flaps or cutaneous grafts for the correction of large eyelid defects. Revista Cubana de Oftalmología [Internet]. 2018 (citado 2020 May 13); 31(4). DOI: http://scielo.sld.cu/scielo.php?script=sci_ arttextsLid $=$ S0864-21762018000400002.

6.Del Vecchyo Calcáneo C, Espinosa Maceda S. Fat grafts in aesthetic facial surgery. Cir Plást Iberolatinoam [Internet]. 2013 (citado 2020 May 3); 39(1):26-8. DOI: http://scielo.isciii.es/scielo. php? script $=$ sci_arttext $\mathcal{L}^{2}$ pid $=$ S0376-78922013000500008

7.Meruane M. Fat grafting: fundamentals and clinical application. CLC [Internet]. 2016 (citado 2020 May 6) 27(1):93-106. DOI: https://www.sciencedirect.com/science/ article/pii/S0716864016000134

8.Fulton J, Parastouk N. Fat Grafting. Facial plastic surgery clinics of north america [Internet]. 2008 (citado 2020 May 17); 16(4):459-65. DOl: https:// www.sciencedirect.com/science/article/abs/pii/ S1064740608000588.

9. Benito Ruiz J, Fontdevila Font J. Guia clinica uso de injertos de tejido adiposo y derivados lipotransferencia. SECPRE [Internet]. 2015 (citado 2020 May 1). Disponible en https://aecep.es/wp-content/ uploads/2018/03/guia-lipotransferencia-REV1-2.pdf.

10.Castro B. Aplicaciones clínicas de las células madre del tejido adiposo. Cir Plást lberolatinoam [Internet]. 2013 (citado 2020 May 12); 39(1):29-32. DOI: http://scielo.isciii.es/pdf/cpil/v39s1/original7.pdf.

11.Bustos Araya $S$, Montenegro Matamoros $Y$, Swirgsde Baltodano C, Trigueros Hernández D, Vargas González R, Mora Román JJ. Isolation of mesenchymal stem cells and their participation in the modulation of the immune response. Tecnología en marcha [Internet]. 2018 (citado 2020 May 7); 31(3):29-40. DOI: https://doi.org/10.18845/ tm.v31i3.3899.

12.Cárdenas C. Autologous fat infiltration: a multifunctional surgical procedure. Cir.plást iberolatinoam [Internet]. 2013 (citado 2020 May 7); 39(1):90-8. DOl: http://scielo.isciii.es/pdf/cpil/v39s1/ original16.pdf
13.Quintana Puerta JE, Cifuentes Hoyos V. Systemic toxicity by local anesthetics. CES Medicina [Internet]. 2014 (citado 2020 May 11); 28(1):107-118. DOI: http:// www.scielo.org.co/pdf/cesm/v28n1/v28n1a09.pdf

14.Rodríguez J, Melo Ceballos PA, Melo Ceballos $D$, Enriquez Rodriguez D. Unusual Manifestations and Treatment of Systemic Toxicity by Lidocaine: Case Report. iMedPub Journals [Internet]. 2018 (citado 2020 May 9); 14(4):8. DOI: https:// www.archivosdemedicina.com/medicina-de-familia/ manifestaciones-inusuales-y-tratamiento-de-la-toxicidadsisteacutemica-por-fidocaina-reporte-de-caso.pdf

15.Arana E, Pérez M, Barret JP. Stem-cells enriched lipofilling in pediatric population with ParryRomberg syndrome. Update. Cir Plást lberolatinoam [Internet]. 2013 (citado 2020 May 19); 39(1):99-106. DOI: http://scielo.isciii.es/pdf/cpil/v39s1/original17.pdf

16.Buenrostro Vásquez C, Buck Soltero JA, Morales Valle LA, Granados Tinajero SO. Anestesia en liposucción de grandes volúmenes. Anestesia en Mexico [Internet]. 2017 (citado 2020 May 25); 29(1):64-76. DOI: http://www.scielo.org.mx/pdflam/ v29s1/2448-8771-am-29-00064.pdf

17.Vallarta Rodríguez R, Ruiz Treviño JJ, Guerrero Burgos $F$. Three-dimensional gluteoplasty by precise volumetry. Cir Plást Iberolatinoam [Internet]. 2016 (citado 2020 May 17); 42(3):321-9. DOI: http:// scielo.isciii.es/pdf/cpil/v42n4/estetica2.pdf

18.Pineda Molina C, Londoño Peláez C. Adipose Tissue Derived Mesenchymal Stem Cells, Isolation And Differentiation Into The Osteogenic Lineage. Rev Ing Biomed [Internet]. 2009 (citado 2020 May 19); 3(5):58-65. DOI: http://www.scielo.org.co/pdf/rinbi) v3n5/v3n5a10.pdf

19.Yu. A, Romanov A, Darevskaya N, Merzlikina V, Buravkova LV. Mesenchymal Stem Cells from Human Bone Marrow and Adipose Tissue: Isolation, Characterization, and Differentiation Potentialities. Cell Technologies in Biology and Medicine [Internet]. 2005 (citado 2020 May 16); 140:138-43. DOI: https:// link.springer.com/article/10.1007/s10517-005-0430-z

20.Salazar Vargas G, Manuel Neyra V, Pitot Álvarez $C$, Muñoz Jáuregui AM. Estudios en neurociencias: aportes para la investigación en cultivo de células madre mesenquimales. Persona [Internet]. 2018 (citado 2020 May 18); 21(1):109-117, DOI: https://doi. org/10.26439/persona2018.n021.1993

21.Pu LL, Coleman SR, Cui X, Ferguson RE, Vasconez $\mathrm{HC}$. Autologous fat grafts harvested and refined by the Coleman technique: a comparative study. Europe PMC [Internet]. 2008 (citado 2020 May 19); 122(3):932-7. DOI: https://europepmc.org/article/ med/18766062

22.Fontes T, Brandão I, Negrão R, João Martins $M$, Monteiro R. Autologous fat grafting: Harvesting techniques. Annals of Medicine and Surgery [Internet]. 2018 (citado 2020 May 17); 36:212-8. DOI: https://doi.org/10.1016/j.amsu.2018.11.005

23.Ruiz B. Fat grafting: variables that influence the viability of the adipocyte and mesenchimal stem cells. Cir Plást Iberolatinoam [Internet]. 2011 (citado 2020 May 4); 37(4):311-8. DOI: http://scielo.isciii.es/pdf/ cpil/v37n4/original1.pdf

24.Lee L, Pu Q. Towards more rationalized approach to autologous fat grafting. JPRAS Journals [internet]. 2012 (citado 2020 May 12); 65(4):413-9. DOI: https:// doi.org/10.1016/j.6jps.2011.09.033 
25.Rodriguez Fontan F, Chahla J, Piuzzi N, Payne K, Muschler G, La Prade R, Pascual Garrido C. Stem and Progenitor Cells for Articular Cartilage Repair. Revista Latinoamericana de Cirugía Ortopédica [Internet]. 2016 (citado 2020 May 17); 1(2):66-76. DOI https://doi.org/10.1016/j.rslaot.2016.10.002

26.Xie Y, Zheng D, Li Q, Chen Y, Lei H, Pu L. The effect of centrifugation on viability of fat grafts: an evaluation with the glucose transport test. Journal of Plastic, Reconstructive \& Aesthetic Surgery [Internet]. 2010 (citado 2020 May 7); 63(3):482-7. DOI: https://doi.org/10.1016/j.6jps.2008.11.056.

27.Sanchez A, Ruiz B, Fontdevila J, Raigosa M. New System of Collecting Fat with a Bottle of Redon Drainage. Plastic and reconstructive surgery [Internet]. 2010. (citado 2020 May 2); 125(1):34-5. DOI: 10.1097/PRS.06013e3181c2a326

28.Ávila Portillo L, Franco Ruiz D, Avila García J, Riveros Arocha A, Sabogal M. Comparison of the viability and growth in stem cell culture obtained from adipose tissue (ADAS) pre and post freeze. Stem Medicina Regenerativa [lnternet]. 2015 (citado 2020 May 20), DOI: http://www.scielo.org.co/pdf/nova/ v13n24/v13n24a03.pdf.

29.Galván Cabrera J, Miranda Rodríguez A, Delgado J, Macías Abraham C, Baganet Cobas A, Rondón Corrales T, González Iglesias A, Socarras Ferrer B, Hernández A, Rivero Jiménez R, Hernández Ramírez P. Isolation and characterization of mesenchymal cells from adipose tissue. Rev cubana Hematol Inmunol Hemoter 30. [Internet]. 2016 (citado 2020 May 18); 32(3). DOI: https://www.medigraphic.com/ pdfs/revcubheminmhem/rch-2016/rch163j.pdf
31.Planas J, Muñoz J, González D. Description of a new closed system to process fat and to obtain nanofat: analysis of clinical and cytometric results. Cir plást lberolatinoam [Internet]. 2017 (citado 2020 May 12); 43(1):23-32. DOI: http://dx.doi.org/10.4321/ S0376-78922017000100004

32.Muñoz Piqueras $F$, Bejarano $P$, Muñoz Bautista $M$, Batalla Salgado C. Self-fat injection of surgical failure after a ledderhose illness. Clinical case. Rev Esp Podol [Internet]. 2018 (citado 2020 May 18); 29(2):8793. DOI: https://www.revesppod.com/Ficheros/214/6/06_ NC_podologia_vol29_n2_mu\%C3\%B1oz.pdf

33.Meruane $M$. Lipoinyección: conceptos básicos y aplicación clínica. Revista Médica Clínica Las Condes [lnternet]. 2016 (citado 2020 May 19); 27(1):93-106. DOI: 10.1016/j.rmclc.2016.01.012

34.Serna Cuéllar E, Santamaría Solís L, Which is the survival of fat grafts on the face? How to quantify it?: Evidence based medicine. Cir Plást Iberolatinoam [Internet]. 2013 (citado 2020 May 17); 39(1):82-9. DOI: http://scielo.isciii.es/pdf/cpil/v39s1/original15.pdf

35. Magno A, Caldeira L, Bienvenido M, Mejía $\mathrm{R}$, Marrou Pautrat W. Autologous fat transfer in localized and multicentric scleroderma. Cir Plást lberolatinoam [Internet]. 2016. (citado 2020 May 17); 42(3):285-92. DOI: http://dx.doi.org/10.4321/S037678922016000300011

36.Enríquez Merino J Martínez Ortega J, Cervantes González M. Implante autólogo de grasa. Presentación de dos casos y revisión de la literatura. Rev Cent Dermatol Pascua [Internet]. 2015 (citado 2020 May 20). 24(2). Disponible en medigraphic.com/ pdfs/derma/cd-2015/cd152d.pdf 